(2) Open Access Full Text Article

REVIEW

\title{
Immune checkpoint inhibitors: the new frontier in non-small-cell lung cancer treatment
}

\author{
This article was published in the following Dove Press journal: \\ OncoTargets and Therapy \\ 16 August 2016 \\ Number of times this article has been viewed
}

\section{Hazem El-Osta \\ Kamran Shahid \\ Glenn M Mills \\ Prakash Peddi \\ Department of Medicine, Division of Hematology-Oncology, Louisiana State University Health Sciences Center, Shreveport, LA, USA}

Correspondence: Hazem El-Osta Department of Medicine, Division of Hematology-Oncology, Louisiana State University Health Sciences Center, I50 I Kings Highway, Shreveport, LA 7I I 04, USA

Tel +I 3186754943

$\mathrm{Fax}+13188131007$

Email helost@lsuhsc.edu

\begin{abstract}
Lung cancer is the major cause for cancer-related death in the US. Although advances in chemotherapy and targeted therapy have improved the outcome of metastatic non-small-cell lung cancer, its prognosis remains dismal. A deeper understanding of the complex interaction between the immune system and tumor microenvironment has identified immune checkpoint inhibitors as new avenue of immunotherapy. Rather than acting directly on the tumor, these therapies work by removing the inhibition exerted by tumor cell or other immune cells on the immune system, promoting antitumoral immune response. To date, two programmed death-1 inhibitors, namely nivolumab and pembrolizumab, have received the US Food and Drug Administration approval for the treatment of advanced non-small-cell lung cancer that failed platinum-based chemotherapy. This manuscript provides a brief overview of the pathophysiology of cancer immune evasion, summarizes pertinent data on completed and ongoing clinical trials involving checkpoint inhibitors, discusses the different strategies to optimize their function, and outlines various challenges that are faced in this promising yet evolving field.
\end{abstract}

Keywords: checkpoint inhibitors, immunotherapy, nivolumab, non-small-cell lung cancer, pembrolizumab, programmed death-1, programmed death ligand-1

\section{Introduction}

Lung cancer continues to be the leading cause of cancer-related death in the US with 221,000 estimated new cases in 2015. ${ }^{1}$ Advancement in chemotherapy drugs over the years only brought modest survival gains. This in many ways has led researchers to look for other forms of treatment, finally developing the field of modern immunooncology. For decades, immunotherapy has been used against cancer that is considered traditionally immunogenic such as melanoma and renal cancer. Although prolonged response to high-dose interleukin-2 was observed in small proportion of these patients, its benefit came at the expense of severe toxicity. Nevertheless, non-small-cell lung cancer (NSCLC) was considered nonimmunogenic based on the failure of interferon, interleukin, and Bacillus Calmette-Guerin treatment to provide any clinical benefit. ${ }^{2,3}$ However, better understanding of the interaction between the immune system and tumor microenvironment (TME) has enabled the development of novel and highly promising immune modulators. ${ }^{4}$ William Coley is credited to be the pioneer whose ideas led to the concept of immunotherapy. In 1891, he found a case of sarcoma that regressed following erysipelas infection. He later developed his famous vaccine, a mixture of killed bacteria, aimed to activate the immune system against cancer. ${ }^{5}$ After many years, our understanding of immune system became clearer and various cytokines were discovered leading to the development of modern immunotherapy. The checkpoint inhibitors are the leading factors for this war against lung cancer, 
which in many ways is the new revolution in lung cancer treatment. Leach et al described the inhibitory function of the checkpoint molecule cytotoxic T-lymphocyte antigen-4 (CTLA-4) promoting T-cell anergy. He showed how blocking CTLA-4 with antibodies could unleash an antitumoral immune response. ${ }^{6}$ This was the turning point that shifted the paradigm from attempting to activate the immune system for instance by vaccinating, to releasing the checkpoints that keep it in negative regulatory mode.

This review summarizes our current knowledge of checkpoint inhibitors, reviews the pertinent results from early and late phase studies of different checkpoint inhibitors when used in metastatic NSCLC, discusses potential strategies to optimize their efficacy, and expands their indication in lung cancer. Finally, it discusses few challenges that are faced during the usage of this new class of immunotherapy.

\section{Cancer resistance against the immune system: role for checkpoint inhibitors}

Cancer utilizes various tricks to evade immune responses. This immune tolerance is maintained by multiple mechanisms, including regulatory immune cells, immunosuppressive chemokines, and immune checkpoints that suppress immune functions.

Different chemokines produced by tumor tissue such as CXCL12 have been demonstrated to recruit immunosuppressive cells such as Treg and myeloid-derived suppressor cells. ${ }^{7}$ These cells release different mediators that impair the function of cytotoxic T-cells and dendritic cells, such as transforming growth factor-beta, interleukin-10, and vascular endothelial growth factor, generating an immuno-tolerant microenvironment. ${ }^{8,9}$ Another unique way in which cancer cells work is by downregulating the expression of surface major histocompatibility complex (MHC) class I antigens, consequently escaping recognition by T-cells. ${ }^{10}$ Schreiber et al postulated that non-silent point mutations leading to antigenic neoepitopes are more frequently lost in cancers compared with silent point mutation unrecognized by T-cells. ${ }^{11}$ This phenomenon termed immunoediting explains why progressively growing cancers continue to do so since they are no longer immunogenic, allowing them to evade the immune surveillance. Immunoediting can be mediated by tumor necrosis factor-alpha. For example, melanoma cells can secrete neural crest antigens instead of gp100 secondary to TNF induced dedifferentiation, rendering cancer cells less recognized by T-cells. ${ }^{12}$

Upregulating certain surface ligands that mediate T-cell anergy such as programmed death ligand 1 (PD-L1) can bring an evasive response. ${ }^{13}$ Indeed, tumor recognition is initiated by antigen-presenting cells (APCs) such as dendritic cells that internalize, process, and then present the tumor antigen through MHC1 expressed on its surface. ${ }^{14,15}$ In turn, APCs migrate to the lymph node and present tumor antigen to T-cells through interaction with T-cell receptor, ${ }^{14}$ resulting in priming and activation of T-cell, a process enhanced by the crosstalk between B7.1 (CD80) or B7.2 (CD86) on APC surface and CD28 on the T-cells. ${ }^{16,17}$ Then, the activated T-cells leave the lymph node, engage with the tumor cells via MHC-antigenTCR interaction, and subsequently release cytotoxic enzymes and cytokines that lead to cancer cell death. T-cell-mediated tumor cell death is regulated by different stimulatory and inhibitory signals. The checkpoint molecules, CTLA-4, programmed death-1 (PD-1), and PD-L1, are among the inhibitory signals that serve as negative feedback signals that dampen the immune response and therefore protect against autoimmunity and inflammation. ${ }^{18}$ Cancer cells exploit this mechanism to evade the immune system. ${ }^{6,19,20}$ CTLA-4 molecules are present primarily at $\mathrm{T}$-cell surface. They compete with $\mathrm{CD} 28$ present on T-cells for binding to B7.1 and B7.2 on the APC surface, inducing an inhibitory signal to T-cells and blocking the costimulatory signal resulting from the binding of B7.1/B7.2 and CD28. ${ }^{21,22}$ They also enhance the immunosuppressive activity of regulatory T-cells (Tregs). On the other hand, PD-1 is a transmembrane receptor expressed primarily on T-cells, B cells, and NK cells. ${ }^{23}$ Unlike CTLA-4 that function predominantly during T-cell priming in the lymph nodes, PD-1 exerts its activity primarily in the TME and delivers an inhibitory signal after binding to its ligands PD-L1 and PD-L2 leading to T-cell inactivation (Figure 1). ${ }^{24} \mathrm{PD}-\mathrm{L} 1$ is expressed on the surface of various tissues including a range of tumor type, T- and B cells, dendritic cells, and macrophages. On the contrary, the expression of PD-L2 is more restricted to macrophages, dendritic cells, and certain tumor cells. ${ }^{25} \mathrm{PD}-\mathrm{L} 1$ is generally not detectable in normal tissues. $\mathrm{CD}^{+}{ }^{+} \mathrm{T}$ helper 1 (TH1) cells and $\mathrm{CD}^{+} \mathrm{T}$-cells in the TME produce interferon- $\gamma$, which, on the one hand, activates tumor killing by macrophages, but, on the other hand, upregulates PD-L1 expression as an adaptive immune-resistance mechanism that turns off effector T-cell function. ${ }^{4,26}$ On the other hand, innate resistance implies the constitutive upregulation of PD-L1 expression through constitutive oncogenic signaling that drives cancer growth such as MAPK, PI3K, EGFR, Wnt, and KIT, or chromosomal instability such as in Hodgkin lymphoma.,27-29

\section{Current status of checkpoint inhibitors}

Several monoclonal antibodies directed against CTLA-4, PD-1, and PD-L1 have been developed (Table 1). To date, 


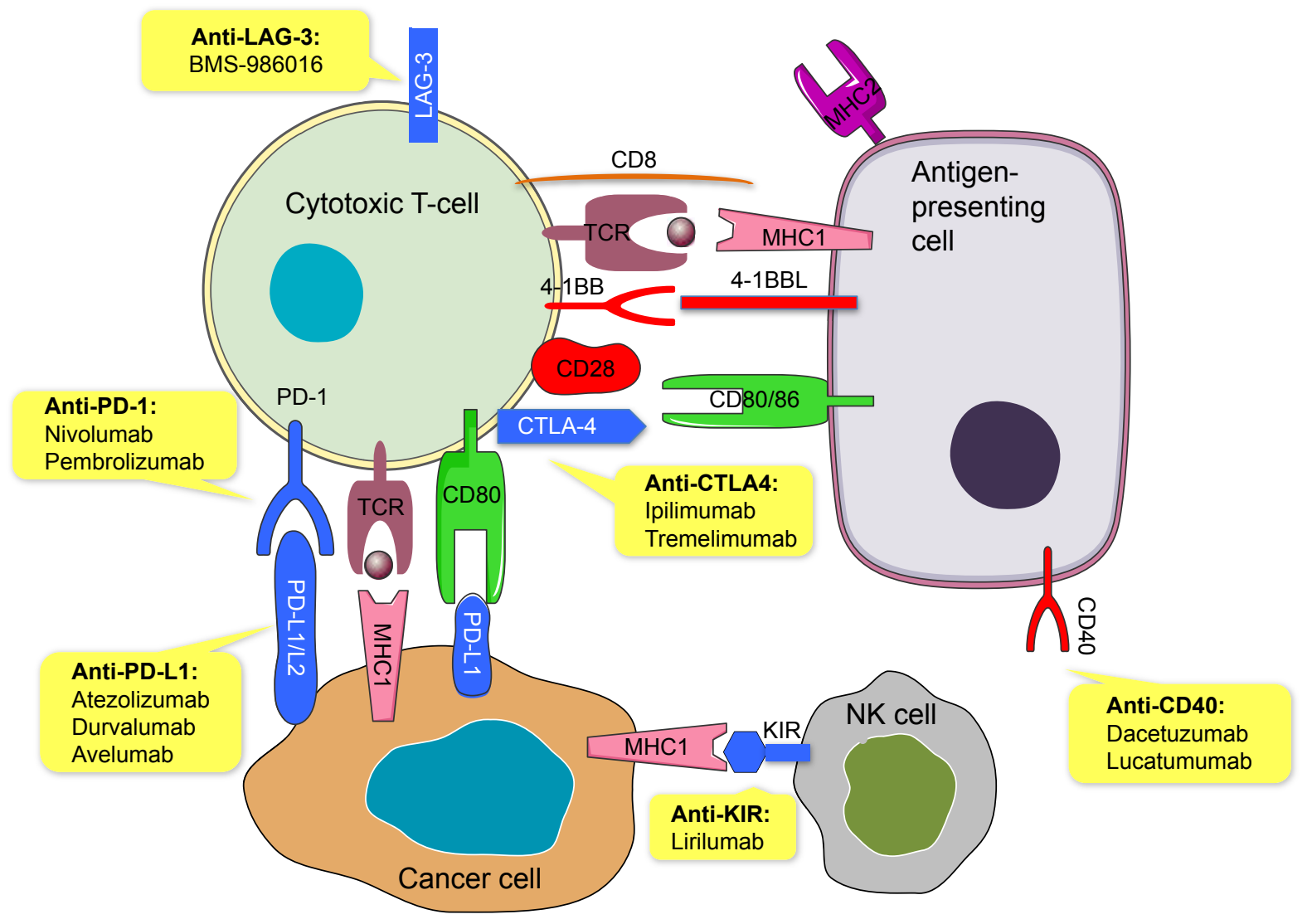

Figure I Image displays the different immune checkpoints between T-cells, APCs, and cancer cells that can be exploited in cancer therapeutics.

Notes: T-cells are activated following the recognition of specific peptides presented by $\mathrm{MHCl}$ at the surface of APCs to their TCR. T-cell activation and proliferation are further enhanced by the costimulatory signal deriving from CD28-CD80/86 interaction and are dampened by CTLA-4-CD80/86 interaction. Anti-CTLA-4 antibody, by releasing the inhibition exerted by CTLA-4-CD80/86 interaction, activates T-cells. Cytotoxic CD8 cells recognize and kill tumor cells after antigenic recognition. Immune checkpoint regulates the interaction among different cells of the immune system to ensure that the activation occurs at the appropriate time and minimizes the possibility of autoimmunity. Cancer cells take advantage of this mechanism to avoid the immune system. For instance, PD-LI and PD-L2 on cancer cell surface bind to PD-I on T-cell surface to deliver an inhibitory signal. PD-LI can also interact with CD80 to exert an inhibitory signal on T-cells. Blockers of PD-LI or PD-I restore T-cell activity within the tumor microenvironment. Costimulatory checkpoints are depicted in red and inhibitory checkpoints are in blue. LAG-3 dampens T-cell differentiation and proliferation following interaction with MHC2, a mechanism that can be reversed with anti-LAG3 antibody. When 4-IBB binds to 4-IBBL or agonist antibodies, it stimulates T-cell activity. KIR expressed on NK cells suppresses their cytotoxic effect after binding to $\mathrm{MHCl}$ found on normal as well as cancer tissues. Anti-KIR antibody can unleash NK cells against cancer cells. CD40 is another costimulatory receptor present on APCs and is required for their activation. It is activated by CD40L expressed on ThI cells. Antibodies directed against CD40 are currently being tested in clinic.

Abbreviations: APC, antigen-presenting cell; KIR, killer immunoglobulin like receptor; LAG-3, lymphocyte activation gene-3; PD-I, programmed death-I; PD-LI, programmed death ligand I; MHCI, major histocompatibility complex I; NK, natural killer; TCR, T-cell receptor; 4-IBB, CDI37; 4-IBBL, 4-IBB ligand.

two checkpoint inhibitors received the US Food and Drug Administration (FDA) approval for previously treated metastatic NSCLC: nivolumab and pembrolizumab. Nivolumab (formerly known as BMS-936558) is a genetically engineered, fully human IgG4 monoclonal antibody with high affinity and specificity for human PD-1. It is engineered to avoid the antibody-dependent cellular cytotoxicity that can lead to T-cell apoptosis and subsequently depletion of activated T-cells. By binding to the $\mathrm{PD}-1$ receptor, it blocks its interaction with PD-L1 and PD-L2 present on the surface of tumor cells and other immune cells notably APC, thereby preventing $\mathrm{T}$-cell inhibition and restoring antitumor immune response. ${ }^{30,31}$ Pembrolizumab (formerly known as MK-3475) is an engineered humanized IgG4 antibody that also selectively targets PD-1 and has two parts: a variable region sequence of a very high-affinity mouse antihuman PD-1 antibody and a human IgG4 immunoglobulin to avoid antibody-dependent cellular cytotoxicity. ${ }^{32}$

\section{Nivolumab - path to FDA approval}

The first major trial involving nivolumab in NSCLC was the CheckMate-003, ${ }^{33}$ a phase I dose escalation study in patients with heavily pretreated advanced NSCLC. Response was noted in all dose levels $(1,3$, and $10 \mathrm{mg} / \mathrm{kg})$. Median OS was 9.9 months across doses, and 14.9 months for the $3 \mathrm{mg} / \mathrm{Kg}$ cohort. The 1-, 2-, and 3-year OS rates were 42\%, 24\% and $18 \%$ respectively among all patients, and $56 \%, 42 \%$, and $27 \%$ respectively at the $3 \mathrm{mg} / \mathrm{Kg}$ dose, which was superior to the other doses and was therefore chosen for further development. Grade 3 and 4 toxicities occurred in $14 \%$ of patients. 
Table I Selected completed clinical trials of PD-I/PD-LI axis inhibitor for the treatment of NSCLC

\begin{tabular}{|c|c|c|c|c|c|}
\hline Trial (NCT) & Phase/setting & Histology & Treatment arm & Outcome & Comments \\
\hline CheckMate- $003^{33}$ & $\begin{array}{l}\text { Phase I/pretreated } \\
\text { advanced NSCLC }\end{array}$ & NSCLC & $\begin{array}{l}\text { Dose escalation of Nivo } \\
(\mathrm{I}, 3 \text {, and } 10 \mathrm{mg} / \mathrm{kg})\end{array}$ & $\begin{array}{l}\text { OS across doses } \\
9.9 \text { months } \\
\text { OS for } 3 \mathrm{mg} / \mathrm{kg} 14.9 \text { months }\end{array}$ & $\begin{array}{l}>50 \% \text { of patients had at } \\
\text { least three lines of therapy }\end{array}$ \\
\hline CheckMate- $063^{34}$ & Phase 2/pretreated & $\begin{array}{l}\text { Squamous } \\
\text { NSCLC }\end{array}$ & Nivo 3 mg/kg & $\begin{array}{l}\text { OS } 8.2 \text { months } \\
\text { I-year OS } 4 \text { I\% }\end{array}$ & $\begin{array}{l}65 \% \text { of patients had failed at } \\
\text { least three lines of therapy }\end{array}$ \\
\hline CheckMate-01735 & Phase 3/pretreated & $\begin{array}{l}\text { Squamous } \\
\text { NSCLC }\end{array}$ & Nivo vs Doc & $\begin{array}{l}\text { OS for Nivo superior to } \\
\text { Doc ( } 9.2 \text { vs } 6.0 \text { months) }\end{array}$ & $\begin{array}{l}\text { PD-LI expression did not } \\
\text { influence Nivo benefit. Led } \\
\text { to first PD-I inhibitor FDA } \\
\text { approval in lung cancer }\end{array}$ \\
\hline CheckMate- $057^{36}$ & Phase 3/pretreated & $\begin{array}{l}\text { Nonsquamous } \\
\text { NSCLC }\end{array}$ & Nivo vs Doc & $\begin{array}{l}\text { OS for Nivo superior to } \\
\text { Doc (I } 2.2 \text { vs } 9.4 \text { months) }\end{array}$ & $\begin{array}{l}\text { PD-LI expression was } \\
\text { associated with improved } \\
\text { survival with Nivo over Doc }\end{array}$ \\
\hline KEYNOTE-00I ${ }^{38}$ & $\begin{array}{l}\text { Phase I/mostly } \\
\text { pretreated }\end{array}$ & NSCLC & $\begin{array}{l}\text { Escalating dose of } \\
\text { pembrolizumab }\end{array}$ & Median OS 12 months & $\begin{array}{l}\text { PD-LI expression } \\
\text { correlated with outcome }\end{array}$ \\
\hline INDI $21564^{40}$ & Phase 2/untreated & NSCLC & Pembrolizumab & CNS RR of $44 \%$ & $\begin{array}{l}\text { PD-LI-positive untreated } \\
\text { brain metastases }\end{array}$ \\
\hline KEYNOTE-01039 & Phase 3/pretreated & $\begin{array}{l}\text { PD-LI expressing } \\
\text { NSCLC }\end{array}$ & $\begin{array}{l}\text { Doc vs pembrolizumab } \\
2 \text { or } 10 \mathrm{mg} / \mathrm{kg}\end{array}$ & $\begin{array}{l}\text { OS for pembrolizumab } \\
\text { longer as compared to Doc }\end{array}$ & $\begin{array}{l}\text { PD-LI }>50 \% \text { associated } \\
\text { with better outcome }\end{array}$ \\
\hline POPLAR $^{41}$ & $\begin{array}{l}\text { Phase } 2 / \text { previously } \\
\text { treated }\end{array}$ & NSCLC & Doc vs atezolizumab & $\begin{array}{l}\text { OS for atezolizumab } \\
\text { superior to } D o c(12.6 \text { vs } \\
9.7 \text { months, } P=0.04)\end{array}$ & $\begin{array}{l}\text { Improved efficacy observed } \\
\text { only in PD-LI-positive } \\
\text { patients }\end{array}$ \\
\hline NCT01693562 42 & $\begin{array}{l}\text { Phase I/2/ } \\
\text { previously treated }\end{array}$ & NSCLC & Durvalumab & ORR I $4 \%$ & $\begin{array}{l}\text { ORR higher in } \\
\text { PD-LI-positive and } \\
\text { squamous histology }\end{array}$ \\
\hline JAVELIN ${ }^{43}$ & $\begin{array}{l}\text { Phase Ib/ } \\
\text { previously treated }\end{array}$ & NSCLC & Avelumab & ORR $13.6 \%$ & $\begin{array}{l}\text { Trend for greater activity } \\
\text { in PD-LI-positive tumor }\end{array}$ \\
\hline
\end{tabular}

Abbreviations: Doc, docetaxel; Nivo, nivolumab; NSCLC, non-small-cell lung cancer; PD-I, programmed death-I; PD-LI, programmed death ligand I; CNS, central nervous system; RR, response rate; ORR, objective response rate; OS, overall survival; FDA, US Food and Drug Administration.

The next important trial was the CheckMate-063. ${ }^{34}$ In this trial, nivolumab demonstrated activity against previously treated patients with advanced squamous NSCLC. Median OS was 8.2 months, PFS rate at 1 year was $20 \%$, and 1 -year OS was $41 \%$. These results are highly promising since $65 \%$ of patients had previously failed three or more lines of therapy.

Major breakthrough was achieved when CheckMate-017 clearly demonstrated superior OS with nivolumab as compared to docetaxel in patients with previously treated advanced squamous NSCLC (9.2 vs 6.0 months, hazard ratio (HR) $0.59,95 \%$ confidence interval $[\mathrm{CI}] 0.44-0.79)$. At 1 year, $42 \%$ of patients in Nivolumab arm were alive as compared to $24 \%$ in the Docetaxel arm. Objective response rate (ORR) was higher with nivolumab (20\% vs 9\%). PD-L1 expression seems not to impact survival benefit. Severe toxicity occurred less frequently with nivolumab ( $7 \%$ vs $55 \%$ ). ${ }^{35}$

In the CheckMate-057 trial, 582 patients with advanced nonsquamous NSCLC who progressed on platinum-based doublet chemotherapy were randomized to docetaxel or nivolumab. ${ }^{36}$ The 1-year PFS was higher with nivolumab $(19 \%$ vs $8 \%)$. OS was more prolonged with nivolumab than with docetaxel (12.2 vs 9.4 months, $P=0.002)$. At 18 months, $39 \%$ of patients in the Nivolumab group were alive as compared to $23 \%$ in the Docetaxel group. ORR was also higher with nivolumab ( $19 \%$ vs $12 \%, P=0.02)$. Severe adverse events (AEs) were observed in $10 \%$ with nivolumab versus $54 \%$ with docetaxel. PD-L1 expression was correlated with improved survival with nivolumab. However, in the subgroup of patients lacking PD-L1 expression, there was no survival benefit for nivolumab over docetaxel. Of note, PD-L1 staining was performed primarily on archived tissue sample. ${ }^{37}$

\section{Pembrolizumab - path to FDA approval}

Pembrolizumab received accelerated FDA approval for the treatment of PD-L1-positive NSCLC that progressed after standard platinum-based chemotherapy. As part of the KEYNOTE 001 trial, ${ }^{38} 495$ patients with advanced NSCLC, $81 \%$ of whom were previously treated, were assigned to various doses of pembrolizumab. Among all patients, the ORR was $19.4 \%$ and the median OS was 12 months. The degree of response and survival correlated with PD-L1 
expression. Among the patients with PD-L1 expression of $>50 \%$, accounting for $23.2 \%$ of screened patients, ORR was $45.2 \%$, median PFS was 6.3 months, and median OS was not reached. In patients with PD-L1 expression between $1 \%$ and $49 \%$ or $<1 \%$, the ORR, PFS, and OS were shorter. Therapy was well tolerated with grade 3-4 toxicities reported in $9.5 \%$ of patients.

Subsequently, the KEYNOTE-010 trial randomized 1,034 previously treated NSCLC patients with PD-L1 expression of at least $1 \%$ of tumor cells to docetaxel, pembrolizumab 2 or $10 \mathrm{mg} / \mathrm{kg}$ every 3 weeks. ${ }^{39}$ OS was significantly longer for pembrolizumab $2 \mathrm{mg} / \mathrm{kg}$ versus docetaxel (10.4 vs 8.5 months, HR 0.71, 95\% CI 0.58-0.88; $P=0.0008$ ) and for pembrolizumab $10 \mathrm{mg} / \mathrm{kg}$ versus docetaxel (12.7 vs 8.5 months, HR $0.61,95 \%$ CI $0.49-0.75 ; P<0.0001$ ). Among patients with at least $50 \%$ PD-L1 expression, OS was significantly prolonged with pembrolizumab $2 \mathrm{mg} / \mathrm{kg}$ than with docetaxel (14.9 vs 8.2 months; HR $0.54,95 \%$ CI $0.38-0.77 ; P=0.0002$ ) and with pembrolizumab $10 \mathrm{mg} / \mathrm{kg}$ than with docetaxel (17.3 vs 8.2 months; HR $0.50,95 \%$ CI 0.36-0.70; $P<0.0001)$. Pembrolizumab was better tolerated, with fewer grade $3-5$ toxicities (13\% for the $2 \mathrm{mg} / \mathrm{Kg}$ dose, $16 \%$ for the $10 \mathrm{mg} / \mathrm{kg}$ dose). Another trial reported $44 \%$ central nervous system response rate achieved with Pembrolizumab in patients with PD-L1 positive NSCLC and untreated brain metastasis. ${ }^{40}$

\section{PD-LI inhibitors: promising data}

No PD-L1 inhibitors have yet been approved for the treatment of NSCLC. Atezolizumab (MPDL3280A), durvalumab (MEDI4736), and avelumab are among the most advanced in clinical development. A randomized phase 2 trial (POPLAR) conducted on patients with recurrent NSCLC revealed median OS of 12.6 months for atezolizumab versus 9.7 months for docetaxel arm $(P=0.04) .{ }^{41}$ In the cohort of patients with any PD-L1 expression, whether in tumor cells or immune cells, a superior OS (HR 0.59, 95\% CI $0.40-0.85 ; P=0.005)$ was noticed with atezolizumab. Patients with no PD-L1 expression did not seem to benefit from atezolizumab.

In a phase $1 / 2$ trial exploring the safety and efficacy of durvalumab, ORR was $14 \%$, which seems to be higher in squamous (21\%) and PD-L1-positive patients (23\%). Grade 3 or 4 AEs occurred in $6 \%$ of cases. ${ }^{42}$ Results from the JAVELIN trial revealed an ORR of $13.6 \%$ and a median OS of 8.4 months in patients with NSCLC treated with avelumab in the second-line setting. A trend for greater efficacy was noticed in PD-L1 expressing tumors. ${ }^{43}$

\section{Safety and toxicities of checkpoint inhibitors}

Checkpoint inhibitors are associated with unique spectrum of toxicities termed immune-related AEs (irAEs). This results from the activation and subsequent infiltration of immune cells into normal tissue. ${ }^{44}$ These immune-related adverse events can affect any organ system such as gastrointestinal tract, lung, liver, and pituitary gland. Whereas irAEs with the usage of ipilimumab in melanoma can occur in 60\%-80\% of patients, their occurrence with PD-1 inhibitors seems to be less frequent and severe. Overall, the toxicity of PD-1 inhibitors is manageable and the occurrence of grade 3 or 4 AEs ranges from $7 \%$ to $17 \% .^{35,36,38,41}$ Similarly, grade 3-4 toxicities associated with single-agent PD-L1 inhibitors range from $6 \%$ to $12 \% .{ }^{45}$ In CheckMate-003 trial, three treatment-related deaths occurred due to pneumonitis (2\%). Treatment-related mortality was $0.2 \%$ for pembrolizumab in the KEYNOTE-001 trial (one death related to pneumonitis), whereas no nivolumab-related death was reported in CheckMate-017 and CheckMate-057 trials.

In general, treatment is based upon the severity of irAE. ${ }^{46}$ Moderate or severe irAEs require interruption of the checkpoint inhibitor and the use of corticosteroid immunosuppression. Grade 2 irAEs (moderate) require withholding the checkpoint inhibitor until toxicity subsides to grade 1 or less. Corticosteroids should be initiated if symptoms do not resolve within a week. For grade 3 or 4 irAEs (severe or life-threatening), checkpoint inhibitors should be permanently discontinued. High doses of corticosteroids should be started and then gradually tapered when toxicity is grade 1 or less. If symptoms do not promptly improve despite intravenous steroids, other potent immunosuppressive agents such as infliximab or mycophenolate mofetil should be considered.

\section{Role for CTLA-4 inhibitor}

Earlier studies showed little to no clinical benefit for single agent CTLA-4 inhibitors in metastatic NSCLC. Compared to best supportive care in recurrent NSCLC, tremelimumab produced only $4.8 \%$ ORR and was associated with significant toxicity. ${ }^{47}$ Focus has shifted to examine their role in synergism with other antineoplastic agents.

In a phase 2 trial, patients with untreated metastatic NSCLC were randomized to receive carboplatin and paclitaxel combined with placebo, concurrent, or phased ipilimumab initiated after two cycles of chemotherapy, which was continued after induction in case of no disease progression. Improvement in ORR and median OS was noticed in the phased ipilimumab group but not in the concurrent arm compared to control. Subgroup 
analysis showed that OS advantage was restricted to squamous histology. ${ }^{48}$ Currently, multiple studies are examining the role of chemo-immunotherapy in patients with squamous NSCLC.

\section{Optimizing checkpoint inhibitor efficacy}

Several preclinical data have shown that chemotherapy and radiation modulate the immune response against tumor by inducing dendritic cell and T-cell activation and MHC1 expression and by lessening the immunosuppressive effect of Treg. ${ }^{49-52}$ Additionally, dual immune checkpoint blockade (ie, anti-PD-1/PD-L1 combined with anti-CTLA-4) allows an increased T-cell responsiveness against tumor. On the basis of this rationale, research has expanded to implicate checkpoint inhibitors in regimens that combined it with other antineoplastic agents or radiation therapy (Tables 2-4).

\section{Combination with chemotherapy}

Although combining anti-PD-1 with other agents may improve antitumor activity, the incidence of side effects is also increased. CheckMate-012, a phase 1 multicohort study, evaluated the safety and efficacy of nivolumab as monotherapy or in combination with various platinum-doublet regimens (cisplatin/gemcitabine, cisplatin/pemetrexed, and carboplatin/paclitaxel) in metastatic untreated NSCLC. The outcome was encouraging with an ORR of 33\%-50\% and 1-year OS of 59\%-87\% across arms. Grade 3-4 treatment-related AEs were reported in $45 \%$ of patients. $^{53}$

The results of phase IB trial combining atezolizumab with chemotherapy (carboplatin plus paclitaxel, pemetrexed, or nab-paclitaxel) in patients with untreated advanced NSCLC revealed an ORR between $60 \%$ and $75 \%$, with no unexpected toxicities being reported. ${ }^{54}$ These combinations are currently being investigated in three different phase 3 trials.

\section{Combination with anti-CTLA-4}

Anti-CTLA-4 and anti-PD-1/PD-L1 enhance T-cell antitumor activity through distinct but complementary mechanisms. Anti-PD-1 releases the inhibition that tumor cells exert on T-cells, and anti-CTLA-4 activates and expands T-cells in lymphoid tissue, bringing them into the tumors. Multiple preclinical data supported the synergism between these two classes of immunotherapy. ${ }^{55-57}$ The combination ipilimumab and nivolumab is associated with increased ORR and PFS compared with ipilimumab single agent in melanoma, at the expense of increased toxicity. ${ }^{58}$

Table 2 Selected completed clinical trials of immune checkpoint inhibitor combined with other antineoplastic agents for the treatment of NSCLC

\begin{tabular}{|c|c|c|c|c|c|}
\hline Trial (NCT) & Phase/setting & Histology & Treatment arm & Outcome & Comments \\
\hline NCT0052773548 & $\begin{array}{l}\text { Phase 2/untreated } \\
\text { NSCLC }\end{array}$ & NSCLC & $\begin{array}{l}\text { Carboplatin, paclitaxel } \\
\text { combined with } \\
\text { placebo, concurrent, } \\
\text { or phased ipilimumab }\end{array}$ & $\begin{array}{l}\text { OS benefit was } \\
\text { observed in phased } \\
\text { ipilimumab group }\end{array}$ & $\begin{array}{l}\text { OS restricted to } \\
\text { squamous histology }\end{array}$ \\
\hline \multirow[t]{4}{*}{ CheckMate-0I $2^{53,59,77,136}$} & $\begin{array}{l}\text { Multiarm phase I/ } \\
\text { untreated NSCLC }\end{array}$ & NSCLC & Nivolumab $^{136}$ & $\begin{array}{l}\text { ORR } 30 \% \\
\text { Median PFS } 29.6 \text { weeks }\end{array}$ & $\begin{array}{l}\text { ORR higher in PD-LI } \\
\text { positive }(67 \%)\end{array}$ \\
\hline & & & $\begin{array}{l}\text { Nivolumab plus various } \\
\text { platinum doublet }^{53}\end{array}$ & $\begin{array}{l}\text { ORR } 33 \%-50 \% \\
\text { I-year OS } 59 \%-87 \%\end{array}$ & Grade $3 / 4$ AE $45 \%$ \\
\hline & & & $\begin{array}{l}\text { Nivolumab plus } \\
\text { ipilimumab }^{59}\end{array}$ & $\begin{array}{l}\text { ORR } 13 \%-39 \% \\
\text { Treatment-related } \\
\text { AEs leading to } \\
\text { discontinuation: } \\
5 \%-13 \%\end{array}$ & $\begin{array}{l}\text { Responses seen } \\
\text { regardless of PD-LI } \\
\text { status, with increased } \\
\text { benefit in PD-LI positive } \\
\text { patients. }\end{array}$ \\
\hline & & & $\begin{array}{l}\text { Nivolumab plus } \\
\text { erlotinib }^{77}\end{array}$ & ORR $19 \%$ & $\begin{array}{l}\text { Most enrollees had } \\
\text { failed erlotinib }\end{array}$ \\
\hline NCT0I $633970^{54}$ & $\begin{array}{l}\text { Phase Ib/untreated } \\
\text { NSCLC }\end{array}$ & NSCLC & $\begin{array}{l}\text { Atezolizumab in } \\
\text { combination with } \\
\text { carboplatin and } \\
\text { paclitaxel, pemetrexed } \\
\text { or nab-paclitaxel }\end{array}$ & $\begin{array}{l}\text { ORR } 67 \% \text { in all groups } \\
\text { combined } \\
\text { ORR } 75 \% \text { in arm } \\
\text { carbo/pemetrexed } \\
\text { with atezolizumab }\end{array}$ & $\begin{array}{l}\text { Three phase III studies } \\
\text { of atezolizumab in } \\
\text { combination with } \\
\text { chemotherapy in NSCLC } \\
\text { have been initiated }\end{array}$ \\
\hline NCT02039674/KEYNOTE-02 ${ }^{61}$ & $\begin{array}{l}\text { Phase I/previously } \\
\text { treated }\end{array}$ & NSCLC & $\begin{array}{l}\text { Pembrolizumab } \\
\text { combined with } \\
\text { ipilimumab }\end{array}$ & $\begin{array}{l}\text { ORR } 55 \% \\
\text { DCR } 100 \%\end{array}$ & No DLT observed \\
\hline NCT0200094762 & $\begin{array}{l}\text { Phase I/immunotherapy } \\
\text { naïve }\end{array}$ & NSCLC & $\begin{array}{l}\text { Durvalumab combined } \\
\text { with tremelimumab }\end{array}$ & $\begin{array}{l}\text { ORR } 23 \% \\
\text { Serious AEs 36\% }\end{array}$ & $\begin{array}{l}\text { Clinical activity } \\
\text { independent of PD-LI } \\
\text { status }\end{array}$ \\
\hline
\end{tabular}

Abbreviations: AE, adverse event; NSCLC, non-small cell lung cancer; PD-LI, programmed death ligand I; carbo, carboplatin; ORR, objective response rate; OS, overall survival; DCR, disease control rate; DLT, dose limiting toxicity. 
Table 3 Selected ongoing clinical trials of PD-I or CTLA-4 inhibitors for the treatment of NSCLC

\begin{tabular}{|c|c|c|c|}
\hline Trial (NCT) & Phase/setting & Histology & Treatment arm \\
\hline NCT02477826/CheckMate-22760 & III/untreated & NSCLC & Nivo vs Nivo/lpi vs Nivo/platinum-doublet chemo vs chemo only \\
\hline NCT02696993 137 & I/II/brain metastasis & NSCLC & Nivo/SRS vs Nivo/lpi/SRS vs Nivo/WBRT vs Nivo/lpi/WBRT \\
\hline NCT0222173970 & II/previously treated & NSCLC & Ipi concurrently with XRT (IMRT or 3D conformal) to metastatic site \\
\hline NCT0223990069 & $\begin{array}{l}\text { I/II/previously treated } \\
\text { or untreated }\end{array}$ & NSCLC & Ipi concurrently or sequentially with SBRT to metastatic site \\
\hline NCT02574078/CheckMate-37085 & II/untreated & NSCLC & $\begin{array}{l}\text { Nonsquamous EGFR/ALK wt did not progress on induction chemo: } \\
\text { Nivo vs SOC maintenance (Bev or Pem) vs Nivo plus SOC } \\
\text { Squamous NSCLC did not progress on induction chemo: } \\
\text { Nivo maintenance vs BSC } \\
\text { EGFR/ALK wt borderline PS: Nivo vs SOC induction chemo } \\
\text { EGFR mutant: Erlotinib with/without Nivo } \\
\text { ALK positive: Crizotinib with/without Nivo }\end{array}$ \\
\hline NCT02393625 138 & $\begin{array}{l}\text { I/previously treated or } \\
\text { untreated }\end{array}$ & $\begin{array}{l}\text { ALK-positive } \\
\text { NSCLC }\end{array}$ & Nivo plus Ceritinib \\
\hline NCT0I928576 82 & II/previously treated & NSCLC & Azacytidine plus entinostat followed by Nivo vs Nivo \\
\hline NCT0204I 533/CheckMate-02683 & III/untreated & $\begin{array}{l}\text { PD-LI-positive } \\
\text { NSCLC }\end{array}$ & Nivo vs platinum-doublet chemotherapy \\
\hline NCT02220894/KEYNOTE-4284 & III/untreated & $\begin{array}{l}\text { PD-LI-positive } \\
\text { NSCLC }\end{array}$ & Pem vs platinum-doublet chemotherapy \\
\hline NCT02066636/CheckMate-I53'134 & III/IV/previously treated & NSCLC & $\begin{array}{l}\text { Nivo until disease progression or unacceptable toxicity vs Nivo for } \\
\text { I year with retreatment allowed }\end{array}$ \\
\hline
\end{tabular}

Abbreviations: Ipi, Ipilimubab; Nivo, nivolumab; NSCLC, non-small cell lung cancer; PD-I, programmed death-I; PD-LI, programmed death ligand I; Pem, pembrolizumab; chemo, chemotherapy; SRS, stereotatic radiosurgery; WBRT, whole brain radiation therapy; XRT, radiation therapy; IMRT, intensity-modulated radiation therapy; SBRT, stereotactic body radiation therapy; BSC, best supportive care; Bev, bevacizumab; EGFR, epidermal growth factor receptor; ALK, anaplastic lymphoma kinase; SOC, standard of care.

In the CheckMate-012 phase 1 trial, nivolumab plus ipilimumab combination led to ORR of $13 \%-39 \%$ across different dosage cohort in advanced NSCLC. Interestingly, clinical activity was observed regardless of PD-L1 status. Treatment-emergent grade 3/4 AEs leading to treatment discontinuation was reported in 5 to $13 \%$ of cases. ${ }^{59}$ The promising response rate rivaling platinum doublet chemo in the frontline therapy has led to the opening of the CheckMate227 trial $^{60}$ evaluating nivolumab monotherapy and nivolumab plus ipilimumab combination regimens versus platinumdoublet chemotherapy in patients with chemotherapy-naïve stage IV or recurrent NSCLC.

Table 4 Selected ongoing clinical trials of PD-LI inhibitors for the treatment of NSCLC

\begin{tabular}{|c|c|c|c|}
\hline Trial (NCT) & Phase/setting & Histology & Treatment arm \\
\hline NCT02409355/IMpower I I I I39 & III/untreated & Squamous & $\begin{array}{l}\text { Atezolizumab (MPDL3280a) vs platinum-doublet } \\
\text { chemo }\end{array}$ \\
\hline NCT02409342/IMpower I I $0^{140}$ & III/untreated & Nonsquamous & Atezolizumab vs platinum-doublet chemotherapy \\
\hline NCT02367794/IMpower I3 I 14I & III/untreated & Squamous & $\begin{array}{l}\text { Atezolizumab plus chemotherapy vs platinum- } \\
\text { doublet chemotherapy }\end{array}$ \\
\hline NCT0236778I/IMpower I30142 & III/untreated & Nonsquamous & $\begin{array}{l}\text { Atezolizumab plus platinum-doublet chemotherapy } \\
\text { vs chemotherapy only }\end{array}$ \\
\hline NCT02453282/MYSTIC ${ }^{143}$ & III/untreated & NSCLC & $\begin{array}{l}\text { Durvalumab plus tremelimumab (CTLA- } 4 \text { inhibitor) } \\
\text { vs durvalumab vs platinum-doublet chemotherapy }\end{array}$ \\
\hline NCT02008227/OAK ${ }^{144}$ & III/previously treated & NSCLC & Atezolizumab vs docetaxel \\
\hline NCT02395 I72/JAVELIN Lung 200145 & III/previously treated & NSCLC & Avelumab vs docetaxel \\
\hline NCT02088II $2^{146}$ & I/EGFR TKI naïve & EGFR mutant NSCLC & Durvalumab (MEDI4736) plus gefitinib \\
\hline NCT02454933/CAURAL 147 & III/previously treated & $\begin{array}{l}\text { EGFR-T790M mutant } \\
\text { NSCLC }\end{array}$ & AZD929I plus durvalumab vs AZD929I \\
\hline NCT02352948/ARCTIC 148 & III/previously treated & NSCLC & $\begin{array}{l}\text { PD-LI positive: SoC treatment vs durvalumab } \\
\text { PD-LI negative: durvalumab/tremelimumab vs } \\
\text { SoC vs durvalumab vs tremelimumab }\end{array}$ \\
\hline NCT02273375 ${ }^{87}$ & III/adjuvant & $\begin{array}{l}\text { NSCLC (resected } \\
\text { stage IB-IIIA) }\end{array}$ & Durvalumab vs placebo \\
\hline NCT02 I 2546I/PACIFIC 91 & $\begin{array}{l}\text { III/consolidation of stage } 3 \\
\text { unresectable disease, no } \\
\text { progression following CXRT }\end{array}$ & NSCLC & Durvalumab vs placebo \\
\hline
\end{tabular}

Abbreviations: NSCLC, non-small cell lung cancer; PD-I, programmed death-I; PD-LI, programmed death ligand I; SoC, standard of care; EGFR, epidermal growth factor receptor; CXRT, chemo-radiation. 
Preliminary results from KEYNOTE-021, a phase 1 trial investigating the combination of pembrolizumab with ipilimumab as second-line therapy in patients with advanced NSCLC reported an ORR of 55\% and disease control rate was seen in all patients $(100 \%) .{ }^{61}$ Similarly, durvalumab (anti-PD-L1) combined with tremelimumab (anti-CTLA-4) has exhibited clinical activity in patients with advanced NSCLC irrespective of PD-L1 status. Serious AEs occurred in $36 \%$ of patients. $^{62}$

\section{Combination with radiation therapy}

Radiation has been reported to induce tumor regression at distance from the irradiated site, a phenomenon called "abscopal effect," 63 believed to be partly T-cell mediated. ${ }^{64}$ The synergism of immunomodulators and radiation is supported by animal and clinical data. ${ }^{65-67}$ Systemic regression of metastatic lesions has been reported in a patient with metastatic melanoma who progressed on ipilimumab and following localized radiation. ${ }^{66}$ Rise in tumor-directed antibody levels and $\mathrm{CD}^{+}{ }^{+} \mathrm{ICOS}^{\text {high }} \mathrm{T}$-cells (activated T-cells) were concordant with the time of the abscopal effect. These surprising findings support the idea that a localized treatment with radiation may broadly stimulate the immune system to fight cancer through induction of tumor antigen presentation and T-cell activation. ${ }^{66}$

Golden et $\mathrm{l}^{65}$ reported another case of refractory NSCLC that experienced an out-of-field effect following treatment with radiation concurrently with ipilimumab, associated with increased tumor infiltrating lymphocytes (TILs). The patient was disease-free 1 year after the treatment.

These observations have led researchers to investigate the efficacy of radiation therapy in combination with checkpoint inhibitors. ${ }^{68}$ For instance, two phase II trials are currently exploring the safety and efficacy of ipilimumab administered concurrently or sequentially to radiation (stereotactic body radiation therapy and intensity-modulated radiation therapy or 3D conformal) in patients with metastatic solid malignancies. ${ }^{69,70}$ Similarly, an ongoing phase I/II trial is studying the safety and efficacy of pembrolizumab in combination with hypofractionated stereotactic radiation therapy in patients with advanced NSCLC. ${ }^{71}$ These results highlight the importance of designing trials that can answer how to best use radiation in combination with immunotherapy.

\section{Combination with targeted agents}

Targeted therapy against driver mutation is associated with very high response rate. Unfortunately, treatment resistance eventually develops within few months. The possible combination of targeted therapy with immunotherapy could presumably allow for a long-lasting response. Targeted therapy can induce rapid tumor regression accompanied by the release of large amounts of antigenic debris. As a result, larger tumor antigen presentation to T-cell by APC can further enhance the immune response and presumably render tumor more sensitive to PD-1/PD-L1 inhibitor. ${ }^{72,73}$ In parallel, EGFR and ALK alterations are associated with increased PD-L1 expression. ${ }^{74,75}$ Akbay et al showed a strong correlation between EGFR activation, PD-L1 upregulation, and T-cell exhaustion in lung cancer cell lines. This process can be reversed with EGFR blockade. ${ }^{27}$ In a cohort of 125 NSCLC patients, PD-1 positivity was strongly associated with KRAS mutation whether PD-L1 expression was strongly associated with the presence of EGFR mutation. ${ }^{76}$

In chemonaïve EGFR mutant NSCLC patients enrolled in the CheckMate-012 trial, erlotinib and nivolumab combination yielded an ORR of 19\%. Among those with acquired resistance to erlotinib, 15\% had partial response and $45 \%$ had stable disease. ${ }^{77}$ The efficacy and safety of nivolumab when used in combination with third-generation EGFR inhibitor in T790M mutation remains to be examined. Multiple ongoing clinical trials are investigating the combination of checkpoint inhibitors and targeted therapy as highlighted in Tables 3 and 4.

\section{Combination with epigenetic modulators}

Epigenetic reprogramming has been shown to alter T-helper 1 type chemokines, whereas treatment with epigenetic modulator induces effector T-cell tumor infiltration and improves efficacy of PD-L1 inhibitors. ${ }^{78}$ Azacytidine upregulates multiple genes involved in immune system evasion, including PD-L1, in lung cancer cell lines. ${ }^{79}$ Other studies have suggested DNA methyltransferases inhibitors as enhancers of cancer cell susceptibility to immune checkpoint inhibitors. ${ }^{80}$ For instance, azacytidine combined with entinostat achieved a median OS of 6.4 months and disease control rate of $41 \%$ in heavily pre-treated advanced NSCLC. ${ }^{81}$ Strikingly, notable clinical response to subsequent anticancer treatments including checkpoint inhibitors was noticed, raising the question whether priming with epigenetic treatment may sensitize tumor to PD1/PD-L1 blockade. A study of priming with azacytidine with or without entinostat prior to treatment with nivolumab is ongoing. ${ }^{82}$

\section{New role for checkpoint inhibitors} First-line and maintenance setting

A large number of clinical trials are currently investigating the role of PD-1 inhibitors in frontline as monotherapy or 
combined with standard chemotherapy. CheckMate-026 trial is comparing nivolumab with investigator choice of platinum-doublet chemotherapy in untreated metastatic or recurrent PD-L1-positive NSCLC. ${ }^{83}$ KEYNOTE-042 and 24 are comparing pembrolizumab with chemotherapy in PD-L1-positive untreated advanced NSCLC. ${ }^{84}$ Similarly, various immune checkpoint inhibitors are in late-stage of development (ie, durvalumab and avelumab), and they are being explored in first-line setting as single agent or combined with chemotherapy (Tables 3 and 4). A groundbreaking trial, CheckMate-370, is a phase I/II master protocol, containing five substudies and enrolling patients with advanced NSCLC. ${ }^{85}$ Nivolumab will be compared to standard of care approach and incorporated in the frontline or maintenance setting according to enrollees' performance status, mutational status, and response to induction chemotherapy.

\section{Adjuvant setting}

Ipilimumab reduces the risk of recurrence in patients with stage III melanoma following complete resection. ${ }^{86}$ The goal of administering immune agent after complete tumor resection is to target any minimal residual disease and therefore reduce the risk of recurrence. As such, an ongoing trial is currently exploring the role of adjuvant durvalumab in completely resected NSCLC. ${ }^{87}$

\section{Locally advanced unresectable setting}

Prognosis of patients with stage III unresectable NSCLC is poor despite advance in radiation technique and incorporation of concurrent chemotherapy. ${ }^{88}$ The role of consolidation chemotherapy is debatable, and two randomized studies have failed to show a survival benefit. ${ }^{89,90}$ An ongoing study is currently assessing the effects of consolidation treatment with durvalumab in stage III unresectable NSCLC patients that have not progressed following concurrent definitive chemoradiation. $^{91}$

\section{Other potential targetable immune checkpoints}

Deeper understanding of the immune system dysfunction in lung cancer has led to the discovery of several additional targetable immune checkpoints and costimulatory receptors (Figure 1). Lymphocyte activation gene-3 (LAG-3), killer immunoglobulin like receptor (KIR), and T-cell immunoglobulin and mucin domain-3 (TIM-3) are among many other immune checkpoints to which inhibitor currently exists and being tested in preclinical or early phase clinical trials. LAG-3 is expressed by lymphocytes and NK cells. By binding to MHCII, LAG-3 enhances Treg activity and dampens T-cell differentiation and proliferation..$^{92,93}$ Dual LAG3 and PD-1 inhibition showed decreased tumor growth and increased antitumor immunity in mice model. ${ }^{94}$ An ongoing phase I trial is investigating anti-LAG-3 alone or in combination with anti-PD-1.95

KIR proteins are expressed by NK cells. By binding to HLA molecules present on normal cells and to a lesser extent on tumor cells, they suppress NK cytotoxic activity. ${ }^{96}$ AntiKIR antibodies, by unleashing NK cells against cancer cells, have shown preclinical activity in different malignancies. ${ }^{97,98}$ Lirilumab is an anti-KIR antibody currently being tested in different malignancies including NSCLC. ${ }^{99,100}$

TIM-3 is expressed by different immune cells, including T-helper-1 (Th1). When TIM-3 binds to its ligand galectin-9, often found on tumors, it results in Th1 apoptosis. ${ }^{101}$ In mouse model, TIM-3 inhibition combined with anti-CTLA-4 or antiPD-1 led to tumor shrinkage. ${ }^{102}$ Increased TIM-3-positive $\mathrm{T}$-cells were described as a mechanism of resistance to PD-1 blockade in mice model. Interestingly, these mice benefit from PD-1 and TIM-3 blockade. ${ }^{103}$

Numerous costimulatory receptors present on different immune cells promote immune cells attack against tumors and are potential therapeutic targets. $4-1 \mathrm{BB}$, also known as CD137, is expressed in many immune cells including T-cells, dendritic cells, and NK cells. When binding to its ligand, 4-1BBL, or agonist antibodies, it stimulates an immune response, particularly anticancer cytotoxic T-cell response. ${ }^{104}$ Agonist 4-1BB antibodies have shown efficacy in preclinical and early clinical data. ${ }^{105,106}$ The development of urelumab, a 4-1BB-agonist antibody, was initially suspended due to fatal hepatotoxicity. It is currently being studied at lower doses both as monotherapy and in combination with other agents in solid tumor and hematologic malignancies. Another 4-1BB agonist antibody, utomilumab (PF-05082566), is currently under clinical development. ${ }^{107}$ Other agonistic molecules undergoing investigation include GITR, CD40, and OX40 agonists. ${ }^{107}$

B7H4 is another less known immune checkpoint expressed on infiltrating myeloid cells and vessels and widely expressed by solid neoplasms. Its overexpression correlates with advanced disease stage and poor prognosis in cancer patients. It is believed to inhibit the activation and proliferation of $\mathrm{T}$ effectors and to induce $\mathrm{T}$-cell arrest. In vivo studies revealed that $\mathrm{B} 7 \mathrm{H} 4$ blockade can reverse the inhibition of tumor-specific T-cells and inhibit tumor growth in lung cancer. ${ }^{108,109}$ 


\section{Potential role of targeting the stroma}

There are different therapeutic strategies aiming to reshape the activity of the tumor stroma (myeloid cells, endothelium, Tregs, etc) in order to enhance the efficacy of T-cell immunotherapy. For instance, myeloid derived suppressor cells create an environment that helps the suppression of effector T-cell activity. ${ }^{110}$ Different approaches aiming to deplete, inhibit, or redirect myeloid derived suppressor cells in cancer to enhance the efficacy of T-cell immunotherapy are underway.

The lack of appropriate innate immune activation required to promote $\mathrm{T}$-cell infiltration can partly explain resistance to PD-1 inhibitors. In many instances, effector T-cells fail to infiltrate the tumor because they are physically impeded by dense stroma or the tumor vasculature. Endothelial cells can inhibit T-cell activity and block them from gaining entry into the tumor through the downregulation of adhesion molecules necessary for T-cell extravasation such as VCAM-1 and ICAM-1. ${ }^{11}$ Indeed, tumor-derived growth factors such as vascular endothelial growth factor and endothelin block the expression of adhesion molecules and inhibit T-cell infiltration into the tumor. ${ }^{111,112}$ On the other hand, endothelium can inhibit T-cell activation by upregulating inhibitory molecules, such as PD-L1 and indoleamine 2,3-dioxygenase. ${ }^{113,114}$ This provides a strong rationale to combine checkpoint inhibitors with inhibitors of vascular endothelial growth factor, indoleamine 2,3-dioxygenase, and immunosuppressant chemokines.

\section{Potential role of targeting Tregs}

Tregs play a crucial role in preventing the activation of $\mathrm{CD}^{+} \mathrm{T}$-cells that have escaped other mechanisms of tolerance. Transforming growth factor-beta1 and interleukin- 2 are the two key cytokines involved in the differentiation of naïve T-cells into Tregs. A higher level of both transforming growth factor-beta1 and interleukin-2 in lung cancer patients suggests that these proinflammatory cytokines might promote the generation and differentiation of Tregs. ${ }^{115-117}$ Accumulated evidence has demonstrated that Tregs correlate with prognosis in lung cancer and represent a key pathogenic player in lung cancer pathogenesis. Tumor Treg cells are reportedly associated with higher risk of recurrence in resected stage 1 NSCLC. ${ }^{118}$ A high Treg/CD8 ${ }^{+}$T-cell ratio is a risk factor for poor response to platinum-based chemotherapy in advanced NSCLC. ${ }^{119}$ In parallel, the drop of Treg levels during neoadjuvant chemoimmunotherapy in NSCLC patients significantly correlates with clinical response. ${ }^{120}$
In vitro findings demonstrated that Treg depletion by the administration of an anti-hCCR $4 \mathrm{mAb}$ abolished the inhibitory effect of Tregs on CD4/CD8 T-cell proliferation. ${ }^{121}$

\section{Challenges of checkpoint inhibitors Biomarker of response}

Biomarkers are needed to guide selecting patients who are most likely to benefit from immunotherapy and to provide early on-treatment indicators of response. Tumor mutational load, intratumoral CD8 ${ }^{+} \mathrm{T}$-cell infiltrates, and tumor PD-L1 expression have been proposed as biomarkers of response to anti-PD-1/PD-L1. ${ }^{26}$

The relevance value of PD-L1 expression is mixed. For instance, in CheckMate-017, PD-L1 expression did not correlate with the outcomes in patients with squamous lung cancer who received nivolumab. ${ }^{35}$ On the other hand, other trials such as KEYNOTE-010 and POPLAR revealed clear association between PD-L1 expression and response. ${ }^{39,41}$ Similarly, in CheckMate-057, the survival advantage of nivolumab over docetaxel in nonsquamous NSCLC was observed with positive PD-L1 expression, whereas the advantage was not observed in patients with $<1 \%$ PD-L1 expression. ${ }^{36}$

The sole use of PD-L1 expression as biomarker for immunotherapy carries multiple caveats. Indeed, numerous factors may affect the interpretation of PD-L1 expression including the affinity and specificity of the used immunostaining antibody, specimen fixation and tissue handling, type of cells looked at to detect PD-L1 positivity (cancer cells or tumor stroma cells), the usage of archival or fresh tissue, tumor heterogeneity, and variability of PD-L1 expression over time. ${ }^{122,123}$

Heterogeneity of tumor may pose many questions about how representative an actionable target detected on tissue biopsy is. ${ }^{124}$ Indeed, focal PD-L1 expression could be easily missed in a small tumor specimen resulting in false negative. Hypothetically, circulating PD-L1 may represent a better surrogate of the PD-L1 status of the whole tumor burden. Zhang et al found that an elevated circulating PD-L1 level is correlated with worse prognosis in NSCLC. ${ }^{125}$ Their usefulness in clinic requires further validation. On the other hand, PD-L1 expression in tumor biopsies collected months earlier might not reflect PD-L1 status at the time of treatment initiation.

Smoking history was suggested as a clinical marker of response to PD-1 inhibitors. A retrospective analysis has shown an ORR of $27 \%$ with nivolumab in current/former smoker patients versus $0 \%$ for minimal/nonsmoker NSCLC patients. ${ }^{126}$ This could be explained by a higher mutational landscape in smokers conferring increased immunogenicity. 
Indeed, a higher nonsynonymous mutation load after exome sequencing correlates with higher ORR and durable clinical benefit with pembrolizumab. ${ }^{127}$ Cancer genomics would inform immunotherapy decision not only by identifying patients with increased immunogenic neoepitopes that are likely to respond to checkpoint inhibitors but also by assisting in creating potent vaccines that potentiate their clinical activity. Implementing novel combination biomarker panels that integrate multiplex immunohistochemistry, genomics, and proteomics may provide stronger predictive value than individual markers for therapeutic outcomes.

\section{Measurement of response}

Unlike traditional cancer treatment, checkpoint inhibitors can be associated with unusual patterns of response, of which the evaluation is more challenging. Since mounting an efficacious anticancer immune response may take a few weeks, such delay can lead to tumor progression initially before occurrence of tumor regression. ${ }^{128}$ Although more often described in ipilimumab-treated melanoma patients, delayed response to $\mathrm{PD} 1 / \mathrm{PD}-\mathrm{L} 1$ in lung cancer is possible. ${ }^{129,130}$ Therefore, the use of RECIST criteria for tumor response assessment in this setting has many limitations including its inability to distinguish pseudo-progression from progression, as well as patients with mixed response or new lesions in whom the overall tumor burden is reduced. Hence, immunerelated response criterion has been established to account for these limitations. ${ }^{131}$ Pseudo-progression occurs subsequent to tumoral lymphocyte infiltration or delayed immune activity. To date, there are no definitive radiologic criteria to differentiate between true progression and pseudo-progression. Developing novel molecular imaging technology to visualize the change in the intratumoral immune response activity that may precede anatomic imaging change is valuable in that matter. Multiple nuclear probes serving to label and identify TILs are currently being tested in clinical trials. ${ }^{132}$

Continuation of anti-PD-1 beyond progression is generally ineffective in NSCLC. Recent retrospective exploratory analysis suggests that only a few patients $(8.3 \%)$ receiving treatment past progression obtain a subsequent partial response. ${ }^{133}$ Unlike targeted therapy and chemotherapy, response to checkpoint inhibitor can be durable, conferring a better outcome. Therefore, it was proposed that 1- or 2-year OS may be a better indicator of efficacy than median OS. ${ }^{37}$

\section{Other unanswered questions}

The optimal duration of treatment and long-term toxicity are yet to be determined. CheckMate-153 is attempting to find the answer by comparing two therapeutic approaches: treatment with nivolumab till progression or unacceptable toxicity versus 1-year treatment and rechallenge upon progression. ${ }^{134}$

A promising yet investigational area is looking at combination immunotherapy tailored to the tumor microenvironment (TME). Smyth et al ${ }^{135}$ suggested to stratify the TME into four types based on the presence of TILs and PD-L1 expression. Type I TME characterized by the presence of PD-L1 and TILs, indicating an adaptive immune resistance, is a phenotype that may benefit the most from PD1/PD-L1 blockade. Type II TME characterized by the absence of PD-L1 and lack of TILs, indicating immune ignorance, is correlated with poor response to checkpoint inhibitors and requires new approaches designed to bring $\mathrm{T}$-cell into the tumor such as dual PD1/PD-L1 and CTLA-4 blockade, use of vaccine or agents that induce $\mathrm{T}$-cell function such as $\mathrm{OX} 40$ and CD137 agonists. Other strategies to attract T-cells into the tumor include chimeric antigen receptor T-cell, combination with chemotherapy or targeted therapy or radiation that promotes immunogenic cell death. Type III TME happens when PD-L1 is expressed constitutively on cancer cells through oncogenic signaling cancers, with the absence of TIL. Although, this group represents only $1 \%$ of melanoma cases, it is more frequent in other cancers such as NSCLC. Without TIL it is unlikely that blocking PD-L1 will lead to T-cell response. A similar approach to type II might be used to try to recruit lymphocytes into the tumor.

Type IV TME tumors contain TILs and lack PD-L1, indicating the role of other suppressor pathways in promoting immune tolerance. This type may benefit from drugs that target checkpoint inhibitors other than PD1/PD-L1 axis such as CTLA-4, KIR, and LAG-3, or other immunosuppressive pathways such as indoleamine 2,3-dioxygenase, and innate immune system (macrophages and myeloid-derived suppressor cells). This concept has to be validated in larger studies incorporating various immune biomarkers.

\section{Authors' opinion}

Patients should be encouraged to participate in clinical trials testing the role of checkpoint inhibitors in different settings: frontline metastatic, maintenance, adjuvant following resection, and locally advanced with or following chemoradiation. Numerous clinical trials are currently being tested or to be open that combine these therapeutic modalities with chemotherapy, radiation therapy, targeted agents, or immune agents (such as anti-CTLA-4, vaccine, CAR-T-cells, etc).

Both pembrolizumab and nivolumab have an established role for patients with metastatic NSCLC who failed 
platinum-based chemotherapy. The decision of selecting which PD-1 blocker to use should be individualized and based upon the preferred treatment schedule and PD-L1 status. For example, for patients with PD-L1 expression $>50 \%$ who prefer an every 3 weeks regimen, treatment with pembrolizumab is suggested. On the other hand, for patients with unknown PD-L1 status, or PD-L1 expression $<1 \%$, nivolumab remains a standard of care regimen.

In selected cases, such as non-smoker patients with symptomatic lung adenocarcinoma of high burden lacking PD-L1 expression, achievement of quick disease response is paramount. Since these patients are less likely to respond to immunotherapy, second-line chemotherapy or targeted therapy may be preferred (docetaxel, plus or minus ramucirumab, pemetrexed, gemcitabine, erlotinib). In such instances, combining immunotherapy and chemotherapy is worth examinng in the context of clinical trials.

Patients with targetable mutations should be treated with their relevant targeting agents. Integrating immune checkpoint inhibitors in their treatment arsenal is being investigated in clinical trials.

\section{Conclusion}

The emergence of immunotherapy in NSCLC has changed the landscape of management of this deadly disease, offering a potential for durable response and survival. The efficacy and good safety profile of immune checkpoint inhibitors have made them a major breakthrough in cancer treatment. Efforts are underway to further define new indications for PD-1/PD-L1 inhibitors in frontline, whether used as single agent, or in combination with other antineoplastic agents, in adjuvant and maintenance settings. Whereas CTLA-4 inhibitors have a limited role when used as monotherapy, integrating their use in combination with other agents will likely further expand their indication in the future.

Several challenges lay ahead. Reliable biomarkers are needed to select the patients who most likely may derive therapeutic benefits. Better tools are needed to distinguish true progression from pseudo-progression, therefore avoiding discontinuation of treatment on patients who likely may have delayed response and allowing change of treatment earlier in patients with true progression. Recognizing the mechanisms of immune resistance to therapeutic PD-1 blockade by interrogating the tumor immune microenvironment is likely to allow the personalized development of immunotherapies tailored to block particular evasion mechanism. This evolving field will promisingly give birth to precision immuno-oncology.

\section{Take home messages}

- Immunologic checkpoint blockade with antibodies against PD-1 or PD-L1 is an effective method for reversing cancer immunosuppression, thereby promoting immune responses against lung cancer.

- Two anti-PD-1 antibodies, pembrolizumab and nivolumab, have been approved by the US FDA for the treatment of previously treated advanced NSCLC.

- Numerous anti-PD-L1 antibodies are under clinical development. Preliminary results have shown superiority of atezolizumab over docetaxel in pretreated advanced NSCLC.

- Ongoing investigations are testing newer combinations, new indications for PD-1/PD-L1 blockers, reliable biomarkers of response, and imaging techniques evaluating their anticancer activity.

- Other targetable immune checkpoint and costimulatory receptors are yet to be discovered.

\section{Disclosure}

The authors report no conflicts of interest in this work.

\section{References}

1. SEER Stat Fact Sheets: Lung and Bronchus Cancer [Webpage on the Internet]. National Cancer Institute. Surveillance, Epidemiology and End Results Program. Available from: http://seer.cancer.gov/statfacts/ html/lungb.html. Accessed August 10, 2016.

2. Schiller JH, Morgan-Ihrig C, Levitt ML. Concomitant administration of interleukin-2 plus tumor necrosis factor in advanced non-small cell lung cancer. Am J Clin Oncol. 1995;18:47-51.

3. Jansen RL, Slingerland R, Goey SH, Franks CR, Bolhuis RL, Stoter G. Interleukin-2 and interferon-alpha in the treatment of patients with advanced non-small-cell lung cancer. J Immunother. 1991;12:70-73.

4. Pardoll DM. The blockade of immune checkpoints in cancer immunotherapy. Nat Rev Cancer. 2012;12:252-264.

5. McCarthy EF. The toxins of William B. Coley and the treatment of bone and soft-tissue sarcomas. Iowa Orthop J. 2006;26:154-158.

6. Leach DR, Krummel MF, Allison JP. Enhancement of antitumor immunity by CTLA-4 blockade. Science. 1996;271:1734-1736.

7. Vianello F, Papeta N, Chen T, et al. Murine B16 melanomas expressing high levels of the chemokine stromal-derived factor-1/CXCL12 induce tumor-specific $\mathrm{T}$ cell chemorepulsion and escape from immune control. J Immunol. 2006;176:2902-2914.

8. Dennis KL, Blatner NR, Gounari F, Khazaie K. Current status of interleukin-10 and regulatory T-cells in cancer. Curr Opin Oncol. 2013; 25:637-645.

9. Fridman WH, Dieu-Nosjean MC, Pages F, et al. The immune microenvironment of human tumors: general significance and clinical impact. Cancer Microenviron. 2013;6:117-122.

10. Catalan E, Charni S, Jaime P, et al; MHC-I modulation due to changes in tumor cell metabolism regulates tumor sensitivity to CTL and NK cells. Oncoimmunology. 2015;4:e985924.

11. Schreiber RD, Old LJ, Smyth MJ. Cancer immunoediting: integrating immunity's roles in cancer suppression and promotion. Science. 2011; 331:1565-1570.

12. Landsberg J, Kohlmeyer J, Renn M, et al. Melanomas resist T-cell therapy through inflammation-induced reversible dedifferentiation. Nature. 2012;490:412-416. 
13. Tumeh PC, Harview CL, Yearley JH, et al. PD-1 blockade induces responses by inhibiting adaptive immune resistance. Nature. 2014;515: $568-571$.

14. Hennecke J, Wiley DC. T cell receptor-MHC interactions up close. Cell. 2001;104:1-4.

15. Vesely MD, Kershaw MH, Schreiber RD, Smyth MJ. Natural innate and adaptive immunity to cancer. Annu Rev Immunol. 2011;29:235-271.

16. Greenwald RJ, Freeman GJ, Sharpe AH. The B7 family revisited. Annu Rev Immunol. 2005;23:515-548.

17. Townsend SE, Allison JP. Tumor rejection after direct costimulation of CD8+ T cells by B7-transfected melanoma cells. Science. 1993;259: 368-370.

18. Vigano S, Perreau M, Pantaleo G, Harari A. Positive and negative regulation of cellular immune responses in physiologic conditions and diseases. Clin Dev Immunol. 2012;2012:485781.

19. Wherry EJ. T cell exhaustion. Nat Immunol. 2011;12:492-499.

20. Hirano F, Kaneko K, Tamura H, et al. Blockade of B7-H1 and PD-1 by monoclonal antibodies potentiates cancer therapeutic immunity. Cancer Res. 2005;65:1089-1096.

21. Chambers CA, Krummel MF, Boitel B, et al. The role of CTLA-4 in the regulation and initiation of T-cell responses. Immunol Rev. 1996; $153: 27-46$

22. Krummel MF, Sullivan TJ, Allison JP. Superantigen responses and co-stimulation: CD28 and CTLA-4 have opposing effects on T cell expansion in vitro and in vivo. Int Immunol. 1996;8:519-523.

23. Keir ME, Butte MJ, Freeman GJ, Sharpe AH. PD-1 and its ligands in tolerance and immunity. Annu Rev Immunol. 2008;26:677-704.

24. Dong H, Strome SE, Salomao DR, et al. Tumor-associated B7-H1 promotes T-cell apoptosis: a potential mechanism of immune evasion. Nat Med. 2002;8:793-800.

25. Rozali EN, Hato SV, Robinson BW, Lake RA, Lesterhuis WJ. Programmed death ligand 2 in cancer-induced immune suppression. Clin Dev Immunol. 2012;2012:656340.

26. Topalian SL, Taube JM, Anders RA, Pardoll DM. Mechanism-driven biomarkers to guide immune checkpoint blockade in cancer therapy. Nat Rev Cancer. 2016;16:275-287.

27. Akbay EA, Koyama S, Carretero J, et al. Activation of the PD-1 pathway contributes to immune escape in EGFR-driven lung tumors. Cancer Discov. 2013;3:1355-1363.

28. Balachandran VP, Cavnar MJ, Zeng S, et al. Imatinib potentiates antitumor $\mathrm{T}$ cell responses in gastrointestinal stromal tumor through the inhibition of Ido. Nat Med. 2011;17:1094-1100.

29. Spranger S, Bao R, Gajewski TF. Melanoma-intrinsic beta-catenin signalling prevents anti-tumour immunity. Nature. 2015;523:231-235.

30. Wang $\mathrm{C}$, Thudium KB, Han M, et al. In vitro characterization of the anti-PD-1 antibody nivolumab, BMS-936558, and in vivo toxicology in non-human primates. Cancer Immunol Res. 2014;2:846-856.

31. Wong RM, Scotland RR, Lau RL, et al. Programmed death-1 blockade enhances expansion and functional capacity of human melanoma antigen-specific CTLs. Int Immunol. 2007;19:1223-1234.

32. Hamid O, Robert C, Daud A, et al. Safety and tumor responses with lambrolizumab (anti-PD-1) in melanoma. $N$ Engl J Med. 2013;369: 134-144.

33. Gettinger SN, Horn L, Gandhi L, et al. Overall survival and long-term safety of nivolumab (anti-programmed death 1 antibody, BMS-936558, ONO-4538) in patients with previously treated advanced non-small-cell lung cancer. J Clin Oncol. 2015;33:2004-2012.

34. Rizvi NA, Mazieres J, Planchard D, et al. Activity and safety of nivolumab, an anti-PD-1 immune checkpoint inhibitor, for patients with advanced, refractory squamous non-small-cell lung cancer (CheckMate 063): a phase 2, single-arm trial. Lancet Oncol. 2015;16:257-265.

35. Brahmer J, Reckamp KL, Baas P, et al. Nivolumab versus docetaxel in advanced squamous-cell non-small-cell lung cancer. $N$ Engl J Med. 2015;373:123-135.

36. Borghaei H, Paz-Ares L, Horn L, et al. Nivolumab versus docetaxel in advanced nonsquamous non-small-cell lung cancer. $N$ Engl J Med. 2015;373:1627-1639.
37. Melosky B, Chu Q, Juergens R, Leighl N, McLeod D, Hirsh V. Pointed progress in second-line advanced non-small-cell lung cancer: the rapidly evolving field of checkpoint inhibition. J Clin Oncol. 2016;34: 1676-1688.

38. Garon EB, Rizvi NA, Hui R, et al. Pembrolizumab for the treatment of non-small-cell lung cancer. $N$ Engl J Med. 2015;372:2018-2028.

39. Herbst RS, Baas P, Kim DW, et al. Pembrolizumab versus docetaxel for previously treated, PD-L1-positive, advanced non-small-cell lung cancer (KEYNOTE-010): a randomised controlled trial. Lancet. 2016;387:1540-1550.

40. Goldberg S, Gettinger S, Mahajan A, et al. Activity and safety of pembrolizumab in patients with metastatic non-small cell lung cancer with untreated brain metastases. J Clin Oncol. 2015;33 (Suppl; abstr 8035).

41. Fehrenbacher L, Spira A, Ballinger M, et al. Atezolizumab versus docetaxel for patients with previously treated non-small-cell lung cancer (POPLAR): a multicentre, open-label, phase 2 randomised controlled trial. Lancet. 2016;387:1837-1846.

42. Rizvi NA, Brahmer JR, Ou S-HI, et al. Safety and clinical activity of MEDI4736, an anti-programmed cell death-ligand 1 (PD-L1) antibody, in patients with non-small cell lung cancer (NSCLC). J Clin Oncol. 2015;33(Suppl; abstr 8032).

43. Gulley JL, Spigel D, Kelly K, et al. Avelumab (MSB0010718C), an anti-PD-L1 antibody, in advanced NSCLC patients: A phase 1b, open-label expansion trial in patients progressing after platinum-based chemotherapy. J Clin Oncol. 2015;33:(Suppl; abstr 8034).

44. Howell M, Lee R, Bowyer S, et al. Optimal management of immunerelated toxicities associated with checkpoint inhibitors in lung cancer. Lung Cancer. 2015;88:117-123.

45. Garon EB. Current perspectives in immunotherapy for non-small cell lung cancer. 2015;42(Suppl 2):S11-S18.

46. Insert Package of Ipilimumab [Webpage on the Internet]. Available from: http://packageinserts.bms.com/pi/pi_yervoy.pdf. Accessed: August 10, 2016.

47. Zatloukal P, Heo D, Park K, et al. Randomized phase II clinical trial comparing tremelimumab (CP-675,206) with best supportive care (BSC) following first-line platinum-based therapy in patients (pts) with advanced non-small cell lung cancer (NSCLC). J Clin Oncol. 2009;27:15s(Suppl; abstr 8071).

48. Lynch TJ, Bondarenko I, Luft A, et al. Ipilimumab in combination with paclitaxel and carboplatin as first-line treatment in stage IIIB/IV non-small-cell lung cancer: results from a randomized, double-blind, multicenter phase II study. J Clin Oncol. 2012;30:2046-2054.

49. Kroemer G, Galluzzi L, Kepp O, Zitvogel L. Immunogenic cell death in cancer therapy. Annu Rev Immunol. 2013;31:51-72.

50. Liu WM, Fowler DW, Smith P, Dalgleish AG. Pre-treatment with chemotherapy can enhance the antigenicity and immunogenicity of tumours by promoting adaptive immune responses. Br J Cancer. 2010;102: $115-123$.

51. Ghiringhelli F, Menard C, Puig PE, et al. Metronomic cyclophosphamide regimen selectively depletes CD4+CD25+ regulatory $\mathrm{T}$ cells and restores $\mathrm{T}$ and $\mathrm{NK}$ effector functions in end stage cancer patients. Cancer Immunol Immunother. 2007;56:641-648.

52. Hanna GG, Coyle VM, Prise KM. Immune modulation in advanced radiotherapies: targeting out-of-field effects. Cancer Lett. 2015;368: 246-251.

53. Antonia S, Brahmer JR, Gettinger S, et al. Nivolumab (anti-PD-1; BMS-936558, ONO-4538) in combination with platinum-based doublet chemotherapy (PT-DC) in advanced non-small cell lung cancer (NSCLC). J Clin Oncol. 2014;32:5s(Suppl; abstr 8113).

54. Liu SV, Powderly JD, Camidge R, et al. Safety and efficacy of MPDL3280A (anti-PDL1) in combination with platinum-based doublet chemotherapy in patients with advanced non-small cell lung cancer (NSCLC). J Clin Oncol. 2015;33(Suppl; abstr 8030).

55. Korman A, Chen B, Wang C, Wu L, Cardarelli P, Selby M. Activity of anti-PD-1 in murine tumor models: role of "host" PD-L1 and synergistic effect of anti-PD-1 and anti-CTLA-4. J Immunol. 2007;178:S82. 
56. Curran MA, Montalvo W, Yagita H, Allison JP. PD-1 and CTLA-4 combination blockade expands infiltrating $\mathrm{T}$ cells and reduces regulatory $\mathrm{T}$ and myeloid cells within B16 melanoma tumors. Proc Natl Acad Sci U S A. 2010;107:4275-4280.

57. Grosso JF, Jure-Kunkel MN. CTLA-4 blockade in tumor models: an overview of preclinical and translational research. Cancer Immun. 2013;13:5.

58. Larkin J, Hodi FS, Wolchok JD. Combined nivolumab and ipilimumab or monotherapy in untreated melanoma. $N$ Engl J Med. 2015;373: $1270-1271$.

59. Hellmann MD, Gettinger SN, Goldman JW, et al. CheckMate 012: Safety and efficacy of first-line (1L) nivolumab (nivo; N) and ipilimumab (ipi; I) in advanced (adv) NSCLC.J Clin Oncol. 2016;34:suppl; abstr 3001.

60. Clinicaltrials.gov. An open-label, trial of nivolumab, or nivolumab plus ipilimumab, or nivolumab plus platinum-doublet chemotherapy versus platinum doublet chemotherapy in subjects with stage IV non-small cell lung cancer (NSCLC) (CheckMate 227), NCT02477826.

61. Patnaik A, Sociniski M, Gubens M, et al; Phase 1 study of pembrolizumab (pembro; MK-3475) plus ipilimumab (IPI) as second-line therapy for advanced non-small cell lung cancer (NSCLC): KEYNOTE021 cohort D. J Clin Oncol. 2015;33(Suppl; abstr 8011).

62. Antonia S, Goldberg SB, Balmanoukian A, et al. Safety and antitumour activity of durvalumab plus tremelimumab in non-small cell lung cancer: a multicentre, phase 1b study. Lancet Oncol. 2016;17:299-308.

63. Prise KM, O'Sullivan JM. Radiation-induced bystander signalling in cancer therapy. Nat Rev Cancer. 2009;9:351-360.

64. Formenti SC, Demaria S. Systemic effects of local radiotherapy. Lancet Oncol. 2009;10:718-726.

65. Golden EB, Demaria S, Schiff PB, et al. An abscopal response to radiation and ipilimumab in a patient with metastatic non-small cell lung cancer. Cancer Immunol Res. 2013;1:365-372.

66. Postow MA, Callahan MK, Barker CA, et al. Immunologic correlates of the abscopal effect in a patient with melanoma. N Engl J Med. 2012; 366:925-931.

67. Deng L, Liang H, Burnette B, et al. Irradiation and anti-PD-L1 treatment synergistically promote antitumor immunity in mice. J Clin Invest. 2014;124:687-695.

68. Crittenden M, Kohrt H, Levy R, et al. Current clinical trials testing combinations of immunotherapy and radiation. Semin Radiat Oncol. $2015 ; 25: 54-64$

69. Clinicaltrials.gov. Ipilimumab and stereotactic body radiation therapy (SBRT) in advanced solid tumors, NCT02239900.

70. Clinicaltrials.gov. Study of combined ionizing radiation and ipilimumab in metastatic non-small cell lung cancer (NSCLC), NCT02221739.

71. Clinicaltrials.gov. MK-3475 and hypofractionated stereotactic radiation therapy in patients with non-small cell lung cancer (NSCLC), NCT02444741.

72. Vanneman M, Dranoff G. Combining immunotherapy and targeted therapies in cancer treatment. Nat Rev Cancer. 2012;12:237-251.

73. Frederick DT, Piris A, Cogdill AP, et al. BRAF inhibition is associated with enhanced melanoma antigen expression and a more favorable tumor microenvironment in patients with metastatic melanoma. Clin Cancer Res. 2013;19:1225-1231.

74. Azuma K, Ota K, Kawahara A, et al. Association of PD-L1 overexpression with activating EGFR mutations in surgically resected nonsmallcell lung cancer. Ann Oncol. 2014;25:1935-1940.

75. Ota K, Azuma K, Kawahara A, et al. Induction of PD-L1 expression by the EML4-ALK oncoprotein and downstream signaling pathways in non-small cell lung cancer. Clin Cancer Res. 2015;21: 4014-4021.

76. D'Incecco A, Andreozzi M, Ludovini V, et al. PD-1 and PD-L1 expression in molecularly selected non-small-cell lung cancer patients. $\mathrm{Br} J$ Cancer. 2015;112:95-102.

77. Rizvi NA, Chow LQM, Borghaei H, et al. Safety and response with nivolumab (anti-PD-1; BMS-936558, ONO-4538) plus erlotinib in patients (pts) with epidermal growth factor receptor mutant (EGFR MT) advanced NSCLC. J Clin Oncol. 2014;32:5s(Suppl; abstr 8022).
78. Peng D, Kryczek I, Nagarsheth N, et al. Epigenetic silencing of TH1type chemokines shapes tumour immunity and immunotherapy. Nature. 2015;527:249-253.

79. Wrangle J, Wang W, Koch A, et al. Alterations of immune response of non-small cell lung cancer with azacytidine. Oncotarget. 2013;4: 2067-2079.

80. Dear AE. Epigenetic modulators and the new immunotherapies. $N$ Engl J Med. 2016;374:684-686.

81. Juergens RA, Wrangle J, Vendetti FP, et al. Combination epigenetic therapy has efficacy in patients with refractory advanced non-small cell lung cancer. Cancer Discov. 2011;1:598-607.

82. Clinicaltrials.gov. Phase II anti-PD1 epigenetic priming study in NSCLC (NA 00084192), NCT01928576.

83. Clinicaltrials.gov. An open-label, randomized, phase 3 trial of nivolumab versus investigator's choice chemotherapy as first-line therapy for stage IV or recurrent PD-L1+ non-small cell lung cancer (CheckMate 026), NCT02041533

84. Clinicaltrials.gov. Study of MK-3475 (pembrolizumab) versus platinum-based chemotherapy for participants with PD-L1-positive advanced or metastatic non-small cell lung cancer (MK-3475-042/ KEYNOTE-042), NCT02220894.

85. Clinicaltrials.gov. A master protocol study of nivolumab in advanced non-small cell lung cancer (NSCLC) (CheckMate 370), NCT02574078.

86. Eggermont AM, Chiarion-Sileni V, Grob JJ, et al. Adjuvant ipilimumab versus placebo after complete resection of high-risk stage III melanoma (EORTC 18071): a randomised, double-blind, phase 3 trial. Lancet Oncol. 2015;16:522-530.

87. Clinicaltrials.gov. Double blind placebo controlled controlled study of adjuvant MEDI4736 in completely resected NSCLC, NCT02273375.

88. Curran WJ Jr, Paulus R, Langer CJ, et al. Sequential vs. concurrent chemoradiation for stage III non-small cell lung cancer: randomized phase III trial RTOG 9410. J Natl Cancer Inst. 2011;103:1452-1460.

89. Hanna N, Neubauer M, Yiannoutsos C, et al. Phase III study of cisplatin, etoposide, and concurrent chest radiation with or without consolidation docetaxel in patients with inoperable stage III non-small-cell lung cancer: the Hoosier Oncology Group and U.S. Oncology. $J$ Clin Oncol. 2008;26:5755-5760.

90. Ahn JS, Ahn YC, Kim JH, et al. Multinational randomized phase III trial with or without consolidation chemotherapy using docetaxel and cisplatin after concurrent chemoradiation in inoperable stage III non-small-cell lung cancer: KCSG-LU05-04. J Clin Oncol. 2015;33: 2660-2666.

91. Clinicaltrials.gov. A global study to assess the effects of MEDI4736 following concurrent chemoradiation in patients with stage III unresectable non-small cell lung cancer (PACIFIC), NCT02125461.

92. Grosso JF, Goldberg MV, Getnet D, et al. Functionally distinct LAG-3 and PD-1 subsets on activated and chronically stimulated CD8 T cells. J Immunol. 2009;182:6659-6669.

93. Kisielow M, Kisielow J, Capoferri-Sollami G, Karjalainen K. Expression of lymphocyte activation gene 3 (LAG-3) on B cells is induced by T cells. Eur J Immunol. 2005;35:2081-2088.

94. Woo SR, Turnis ME, Goldberg MV, et al. Immune inhibitory molecules LAG-3 and PD-1 synergistically regulate T-cell function to promote tumoral immune escape. Cancer Res. 2012;72:917-927.

95. Clinicaltrials.gov. Safety study of anti-LAG-3 with and without antiPD-1 in the treatment of solid tumors, NCT01968109.

96. Gras Navarro A, Bjorklund AT, Chekenya M. Therapeutic potential and challenges of natural killer cells in treatment of solid tumors. Front Immunol. 2015;6:202.

97. Kohrt HE, Thielens A, Marabelle A, et al. Anti-KIR antibody enhancement of anti-lymphoma activity of natural killer cells as monotherapy and in combination with anti-CD20 antibodies. Blood. 2014;123: 678-686.

98. Romagne F, Andre P, Spee P, et al. Preclinical characterization of 1-7F9, a novel human anti-KIR receptor therapeutic antibody that augments natural killer-mediated killing of tumor cells. Blood. 2009;114: 2667-2677. 
99. Clinicaltrials.gov. A phase I study of an anti-KIR antibody in combination with an anti-PD1 antibody in patients with advanced solid tumors, NCT01714739.

100. Clinicaltrials.gov. Safety study in nivolumab alone and in combination with ipilimumab or lirilumab in lymphoma and multiple myeloma, NCT01592370.

101. Sabatos CA, Chakravarti S, Cha E, et al. Interaction of Tim-3 and Tim-3 ligand regulates $\mathrm{T}$ helper type 1 responses and induction of peripheral tolerance. Nat Immunol. 2003;4:1102-1110.

102. Ngiow SF, von Scheidt B, Akiba H, Yagita H, Teng MW, Smyth MJ. Anti-TIM3 antibody promotes T cell IFN-gamma-mediated antitumor immunity and suppresses established tumors. Cancer Res. 2011;71: 3540-3551.

103. Koyama S, Akbay EA, Li YY, et al. Adaptive resistance to therapeutic PD-1 blockade is associated with upregulation of alternative immune checkpoints. Nat Commun. 2016;7:10501.

104. Vinay DS, Kwon BS. 4-1BB signaling beyond T cells. Cell Mol Immunol. 2011;8:281-284.

105. Hernandez-Chacon JA, Li Y, Wu RC, et al. Costimulation through the CD137/4-1BB pathway protects human melanoma tumor-infiltrating lymphocytes from activation-induced cell death and enhances antitumor effector function. J Immunother. 2011;34:236-250.

106. Melero I, Shuford WW, Newby SA, et al. Monoclonal antibodies against the 4-1BB T-cell activation molecule eradicate established tumors. Nat Med. 1997;3:682-685.

107. Bustamante Alvarez JG, Gonzalez-Cao M, Karachaliou N, et al. Advances in immunotherapy for treatment of lung cancer. Cancer Biol Med. 2015;12:209-222.

108. Zou W, Chen L. Inhibitory B7-family molecules in the tumour microenvironment. Nat Rev Immunol. 2008;8:467-477.

109. Chen C, Qu QX, Shen Y, et al. Induced expression of B7-H4 on the surface of lung cancer cell by the tumor-associated macrophages: a potential mechanism of immune escape. Cancer Lett. 2012;317:99-105.

110. Gabrilovich DI, Nagaraj S. Myeloid-derived suppressor cells as regulators of the immune system. Nat Rev Immunol. 2009;9:162-174.

111. Mauge L, Terme M, Tartour E, Helley D. Control of the adaptive immune response by tumor vasculature. Front Oncol. 2014;4:61.

112. Buckanovich RJ, Facciabene A, Kim S, et al. Endothelin B receptor mediates the endothelial barrier to $\mathrm{T}$ cell homing to tumors and disables immune therapy. Nat Med. 2008;14:28-36.

113. Rodig N, Ryan T, Allen JA, et al. Endothelial expression of PD-L1 and PD-L2 down-regulates CD8+ T cell activation and cytolysis. Eur J Immunol. 2003;33:3117-126.

114. Moon YW, Hajjar J, Hwu P, Naing A. Targeting the indoleamine 2,3dioxygenase pathway in cancer. J Immunother Cancer. 2015;3:51.

115. Woo EY, Yeh H, Chu CS, et al. Cutting edge: Regulatory T cells from lung cancer patients directly inhibit autologous $\mathrm{T}$ cell proliferation. J Immunol. 2002;168:4272-4276.

116. Erfani N, Mehrabadi SM, Ghayumi MA, et al. Increase of regulatory T cells in metastatic stage and CTLA-4 over expression in lymphocytes of patients with non-small cell lung cancer (NSCLC). Lung Cancer. 2012;77:306-311.

117. Ganesan AP, Johansson M, Ruffell B, et al. Tumor-infiltrating regulatory $\mathrm{T}$ cells inhibit endogenous cytotoxic $\mathrm{T}$ cell responses to lung adenocarcinoma. J Immunol. 2013;191:2009-2017.

118. Petersen RP, Campa MJ, Sperlazza J, et al. Tumor infiltrating Foxp3+ regulatory $\mathrm{T}$-cells are associated with recurrence in pathologic stage I NSCLC patients. Cancer. 2006;107:2866-2872.

119. Liu H, Zhang T, Ye J, et al. Tumor-infiltrating lymphocytes predict response to chemotherapy in patients with advance non-small cell lung cancer. Cancer Immunol Immunother. 2012;61:1849-1856.

120. Pircher A, Gamerith G, Amann A, et al. Neoadjuvant chemoimmunotherapy modifies CD4(+)CD25(+) regulatory T cells (Treg) in non-small cell lung cancer (NSCLC) patients. Lung Cancer. 2014;85: 81-87.

121. Kurose K, Ohue Y, Sato E, et al. Increase in activated Treg in TIL in lung cancer and in vitro depletion of Treg by ADCC using an antihuman CCR4 mAb (KM2760). J Thorac Oncol. 2015;10:74-83.
122. Omori S, Kenmotsu H, Abe M, et al. Changes in PD-L1 expression in non-small cell lung cancer by immunohistochemical analysis. J Clin Oncol. 2015;33(Suppl; abstr e22118).

123. Brahmer JR, Hammers H, Lipson EJ. Nivolumab: targeting PD-1 to bolster antitumor immunity. Future Oncol. 2015;11:1307-1326.

124. Zhang J, Fujimoto J, Zhang J, et al. Intratumor heterogeneity (ITH) of lung adenocarcinomas defined by multiregion whole exome sequencing (WES). J Clin Oncol. 2014;32:5s(Suppl; abstr 11032).

125. Zhang J, Gao J, Li Y, et al. Circulating PD-L1 in NSCLC patients and the correlation between the level of PD-L1 expression and the clinical characteristics. Thorac Cancer. 2015;6:534-538.

126. Hellmann M, Creelan BC, Woo K, et al. Smoking history and response to nivolumab in patients with advanced NSCLCs. Ann Oncol. 2014;25(Suppl 4):429.

127. Rizvi NA, Hellmann MD, Snyder A, et al. Cancer immunology. Mutational landscape determines sensitivity to PD-1 blockade in non-small cell lung cancer. Science. 2015;348:124-128.

128. Oxnard GR, Morris MJ, Hodi FS, et al. When progressive disease does not mean treatment failure: reconsidering the criteria for progression. J Natl Cancer Inst. 2012;104:1534-1541.

129. Saenger YM, Wolchok JD. The heterogeneity of the kinetics of response to ipilimumab in metastatic melanoma: patient cases. Cancer Immun. 2008;8:1.

130. Topalian SL, Hodi FS, Brahmer JR, et al. Safety, activity, and immune correlates of anti-PD-1 antibody in cancer. N Engl J Med. 2012;366: 2443-2454.

131. Wolchok JD, Hoos A, O'Day S, et al. Guidelines for the evaluation of immune therapy activity in solid tumors: immune-related response criteria. Clin Cancer Res. 2009;15:7412-7420.

132. Juergens RA, Zukotynski KA, Singnurkar A, et al. Imaging biomarkers in immunotherapy. Biomark Cancer. 2016;8:1-13.

133. Kazandjian DG, Blumenthal GM, Khozin S, et al. Characterization of patients treated with a programmed cell death protein 1 inhibitor (antiPD-1) past RECIST progression from a metastatic non-small cell lung cancer (mNSCLC) trial. Clin Oncol. 2016;34(Suppl; abstr 3000).

134. Clinicaltrials.gov. A safety trial of nivolumab (BMS-936558) in subjects with advanced or metastatic non-small cell lung cancer who have progressed during or after receiving at least one prior systemic regimen (CheckMate 153), NCT02066636.

135. Smyth MJ, Ngiow SF, Ribas A, Teng MW. Combination cancer immunotherapies tailored to the tumour microenvironment. Nat Rev Clin Oncol. 2016;13:143-158.

136. Gettinger SN, Sheperd FA, Antonia S, et al. First-line nivolumab (anti-PD-1; BMS-936558, ONO-4538) monotherapy in advanced NSCLC: safety, efficacy, and correlation of outcomes with PD-L1 status. J Clin Oncol. 2014;32:5s(Suppl; abstr 8024).

137. Clinicaltrials.gov. Phase I/II trial of nivolumab with radiation or nivolumab and ipilimumab with radiation for the treatment of intracranial metastases from non-small cell lung cancer, NCT02696993.

138. Clinicaltrials.gov. Study of safety and efficacy of ceritinib in combination with nivolumab in patients with ALK-positive non-small cell lung cancer, NCT02393625.

139. Clinicaltrials.gov. A study of atezolizumab (MPDL3280A) compared with gemcitabine + cisplatin or carboplatin in patients with stage IV squamous non-small cell lung cancer [IMpower111], NCT02409355.

140. Clinicaltrials.gov. A comparative study of atezolizumab (MPDL3280A) with cisplatin or carboplatin + pemetrexed in patients with stage IV non-squamous non-small cell lung cancer (NSCLC) [IMpower110], NCT02409342.

141. Clinicaltrials.gov. A phase III study of MPDL3280A (anti-PD-L1) in combination with carboplatin + paclitaxel or carboplatin + nab-paclitaxel compared with carboplatin + nab-paclitaxel in patients with stage IV squamous non-small cell lung cancer (NSCLC) [IMpower 131], NCT02367794

142. Clinicaltrials.gov. A phase III study of MPDL3280A (anti-PD-L1 antibody) in combination with carboplatin + nab-paclitaxel in patients with non-squamous non-small cell lung cancer [IMpower 130], NCT02367781. 
143. Clinicaltrials.gov. Phase III open label first line therapy study of MEDI 4736 with or without tremelimumab versus SOC in non small-cell lung cancer (NSCLC) (MYSTIC), NCT02453282.

144. Clinicaltrials.gov. A randomized phase 3 study of atezolizumab (an engineered anti-PDL1 antibody) compared to docetaxel in patients with locally advanced or metastatic non-small cell lung cancer who have failed platinum therapy - "OAK", NCT02008227.

145. Clinicaltrials.gov. Avelumab in non-small cell lung cancer (JAVELIN Lung 200), NCT02395172.
146. Clinicaltrials.gov. MEDI4736 (anti PD-L1) combined with gefitinib in subjects with non-small cell lung cancer (NSCLC), NCT02088112.

147. Clinicaltrials.gov. Study of AZD9291 plus MEDI4736 versus AZD9291 monotherapy in NSCLC after previous EGFR TKI therapy in T790M mutation positive tumours (CAURAL), NCT02454933.

148. Clinicaltrials.gov. A global study to assess the effects of MEDI4736, given as monotherapy or in combination with tremelimumab determined by PD-L1 expression versus standard of care in patients with locally advanced or metastatic non small cell lung cancer (ARCTIC), NCT02352948.

\section{Publish your work in this journal}

OncoTargets and Therapy is an international, peer-reviewed, open access journal focusing on the pathological basis of all cancers, potential targets for therapy and treatment protocols employed to improve the management of cancer patients. The journal also focuses on the impact of management programs and new therapeutic agents and protocols on

\section{Dovepress}

patient perspectives such as quality of life, adherence and satisfaction The manuscript management system is completely online and includes a very quick and fair peer-review system, which is all easy to use. Visit http://www.dovepress.com/testimonials.php to read real quotes from published authors.

Submit your manuscript here: http://www.dovepress.com/oncotargets-and-therapy-journal 